\title{
The Effect of Music Therapy on Sense of Loneliness and Life Expectancy in Methamphetamine-Addicted Individuals Attempting to Quit
}

\author{
Reza Mohammadirad ${ }^{1,}{ }^{*}$, Abas Ali Hosseinkhanzadeh ${ }^{1}$, Azra Zebardast ${ }^{1}$ and Hamed Salimi ${ }^{2,3}$ \\ ${ }^{1}$ Department of Psychology, University of Guilan, Rasht, Iran \\ ${ }^{2}$ Oxford University, London, UK \\ ${ }^{3}$ Chalous Branch, Islamic Azad University, Chalous, Iran \\ "Corresponding author: Department of Psychology, University of Guilan, Rasht, Iran. Email: rm1759278@gmail.com
}

Received 2020 April 26; Revised 2020 November 16; Accepted 2020 December 01.

\begin{abstract}
Background: Since there has been no research on music therapy in a systematic way so far to develop motivation and hope in the course of treating individuals who are addicted to drugs, especially stimulant drugs whose use has increased in Iran, the present research was conducted to examine the effect of music therapy on the sense of loneliness and life expectancy in methamphetamineaddicted individuals who were attempting to quit.

Methods: The research is pretest, posttest, and test and control groups. The research sample includes 30 methamphetamineaddicted individuals who were quitting in a midterm residential center in Sowme'eh Sara who were selected by convenience sampling and allocated to two control $(\mathrm{N}=15)$ and experiment $(\mathrm{N}=15)$ groups randomly. UCLA sense of loneliness scale and Schneider statistical questionnaire (1991) were used for data collection.

Results: Studies showed that music therapy could reduce the symptoms related to the sense of loneliness and increased life expectancy $(\mathrm{P}<0.001)$.

Conclusions: It is concluded that mental health professionals can use group music therapy to improve sense of loneliness and life expectancy in methamphetamine-addicted individuals attempting to quit. Also, it is suggested that future research should investigate the effectiveness of group music therapy in improving other psychological constructs in addicted females and males who are attempting to quit.
\end{abstract}

Keywords: Music Therapy, Sense of Loneliness, Life Expectancy, Methamphetamine

\section{Background}

Addiction is considered a fundamental crisis in the present era, which is increasingly developing among the young generation. The use of meth, which is a stimulant drug in the methamphetamines group, is a major problem of public health, and its long-term use can lead to various psychological consequences such as hallucinations, delusions, depression, suicide, and aggression $(1,2)$. In recent years, the country is facing a challenge regarding the shift in the use of patterns from traditional drugs to industrial ones. According to researches, $8 \%$ of drug users are addicted to meth (3). The application of on-time and proper treatment approaches are among significant issues, which should be considered after the diagnosis of disorders related to substance use (4).

Using music as a method to treat addiction dates back to 1970 (5). Studies show that music therapy is effective in reducing symptoms related to senses of loneliness and de- pression (6-9). Using music therapy is effective in enhancing the motivation and life expectancy in a drug-addicted person and generally an individual who is in the process of therapy and rehabilitation (10). According to what was mentioned above, it is possible to use music therapy plans in addiction quitting or group rehabilitation sessions (11). All people trying to treat the addiction face a sense of loneliness. This painful emotional experience is exhibited with more severity in addicted individuals compared to the general population; they are weaker in terms of physical and mental health that is associated with this level of loneliness (12). Sense of loneliness can lead to depression (13), which is considered a major predictor variable for highrisk behaviors (14). By withdrawing from the social environment, the addicted person develops a sense of loneliness and social alienation (15). On the other hand, the motivation in an addicted person to achieve personal goals and desires reduces gradually, which, in turn, affects his/her effective role in society and leads to a lack of life expectancy 
(16). Since active involvement of the addicted person in the treatment course is a fundamental factor, hope is regarded as a very significant predictor factor in treatment, rehabilitation, and recovering mental health of individuals addicted to drugs (16).

The innovative aspect of this research is music therapy method, which has not been performed in a systematic way so far, while each method was applied separately in previous researches. Moreover, the necessity of highlighting the notions of motivation and hope in the process of treatment of addiction, especially in individuals addicted to stimulant substances that experience an increasing trend in Iran by using novel therapies and responding to their mental and existential needs, are considered the research gaps in this field of study. Therefore, the results of this study can be applied as a promising perspective in planning institutions and organizations supporting the consumer.

\section{Objectives}

The aim of this study was to investigate the effect of music therapy methods on reducing the sense of loneliness and increasing life expectancy in individuals quitting meth addiction.

\section{Methods}

In a quasi-experimental study of pre-test-post-test type with a control group, 30 men consuming crystal material in the age range of 20 to 30 years in the city of Soomehsara in 2016 - 2017, who voluntarily went to one of the residential centers in 1996-95. They paid in the medium term. Inclusion criteria were type of consumables (crystal), male gender, and age between 20 - 30 years. Exclusion criteria also were withdrawal and non-cooperation of each member of the group from continuing the treatment process, lack of appropriate physical or mental conditions in each member to continue working. Data collection tools included the UCLA Loneliness Scale (Russell 1980) and life expectancy (Schneider 1991). The UCLA Loneliness Scale was developed by Russell and Pilva, and Cortona (1980) and consists of 20 questions in four options, 10 negative sentences, and 10 positive sentences. The items of this questionnaire are scored on a 4-point Likert scale (never score (1), rarely score (2), sometimes score (3) and always score (4). Moreover, 5, 6, 9, 10, 15, 16, 19, 20 are the other ways around, the range of scores is between 20 (minimum) and 80 (maximum). As reported by Russell, Pilva, and Ferguson (1978) 0.89. This test was translated by Shokrkan and Mirdrikund (2008) and used after preliminary implementation and corrections (17). Schneider(1991)
Life expectancy scale is also a 12-point scale with 8 Likert scores from strongly disagree (1 point) to strongly agree (8) points. Agent thinking subscale consists of four questions $2,9,10,12$ : The path subscale consists of four questions 1 , 4, 7, 8 and four questions 3, 5, 6, 11 as deviant questions that are scored for increased test accuracy is eliminated'. Lopez and Schneider (2007) reported internal consistency through Cronbach's alpha of 0.74 to 0.84 and its validity coefficient by retest method 0.80 and psychometric properties of the Persian version of this scale in Iran by Kermani, Khodapnahi, and Heidari (2011) and in Tehran students, the validity coefficient of this scale was 0.86 using Cronbach's alpha formula and 0.81 through retesting (18).

Sampling was done by available selection method. In order to conduct the study, after referring to one of the medium-term accommodation centers of Sowme'eh Sara city, out of 50 people leaving the materials, after an individual interview and according to the existing background regarding the sample size (4), 30 people Who volunteered to attend the meetings and met the inclusion criteria were selected.

To carry out the research, after referring to a mid-term welfare residential center in Sowme'eh Sara, sample size was determined based on Nademi's study (7). Thirty individuals were selected out of 50 men who were quitting the drug and volunteered to participate in sessions, and had the criteria to enter the study. Initially, the questionnaires of sense of loneliness and life expectancy were performed one week before pretest intervention for test and control groups. The incorporated method of music therapy) type of music was pop music (with oriental themes) was administered in the experimental group for ten 60minute sessions ( 2 weeks 4 sessions and 1 week 2 sessions), while control group received no intervention (Table 1). It should be mentioned that Standley's music therapy package, along with guided imagination, was used in this study (19). Passive music therapy (hearing) was used along with guided imagination. Discussion was used for feelings and notes related to music lyrics. In music therapy with guided imaginations, the participants in the experimental group were asked to focus their attention totally on the clip which was playing and keep their concentration. Moreover, music therapist guided the mental conceptualization of participants during the music therapy process. Motivating clips were selected from instrumental music "songs of the heart" to be played in each session.

\subsection{Statistical Analysis}

The results were entered into SPSS 16 software Kolmogorov-Smirnov test (K-S Z) test were used for determine of quantitative variable, respectively. P-value < 0.05 was considered significant. 


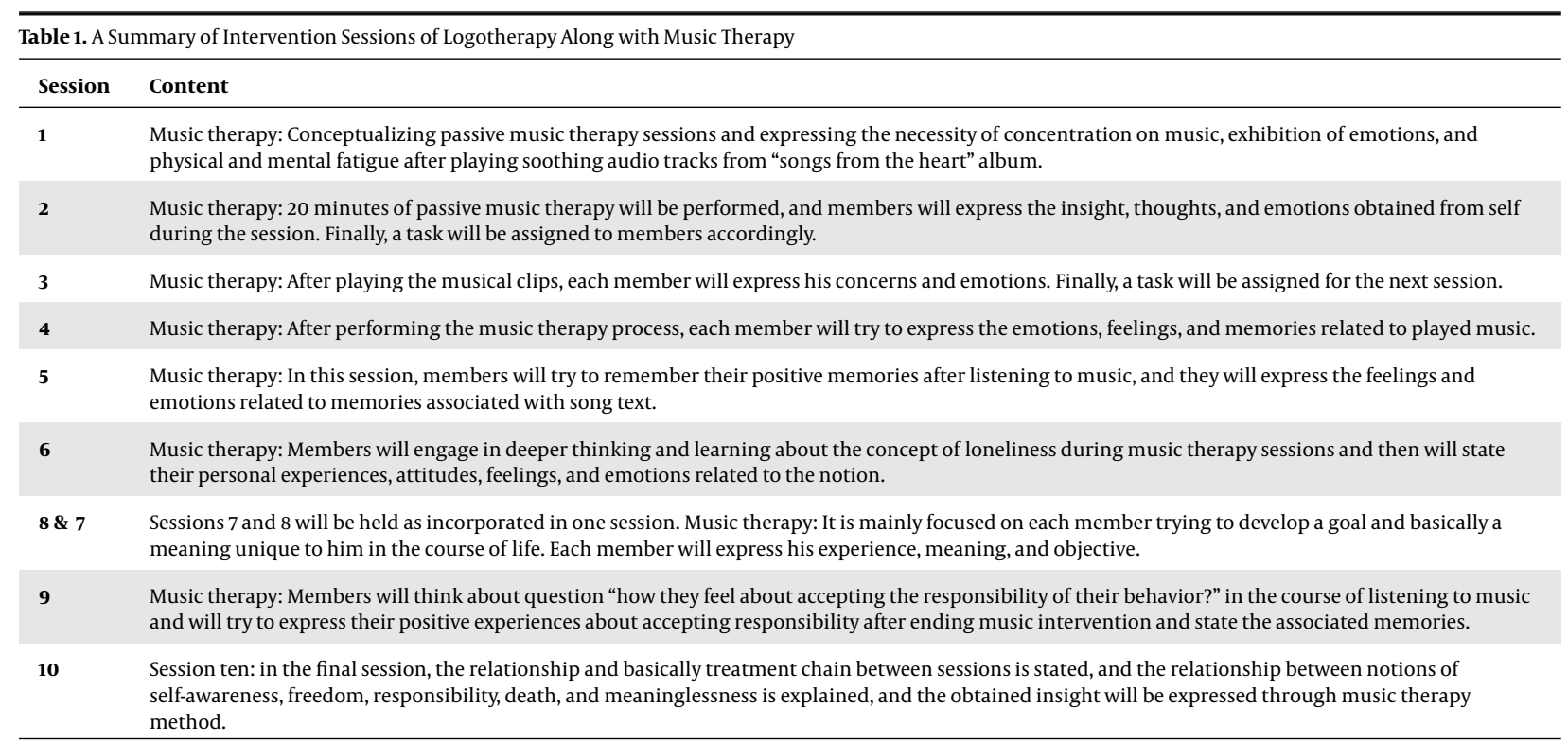

\section{Results}

The mean and standard deviance of pretest-posttest scores of research variables are presented in two control and experimental group (30 men with meth addiction ranging 20-30 years) in Table 2. Moreover, the result of Kolmogorov-Smirnov test (K-S Z) test is reported to study the normality of the distribution of variables in groups. Therefore, it can be concluded that the distribution of variables is normal, and it is possible to use parametric tests such as covariance analysis to analyze these variables.

One-way Covariance analysis (Table 3) was used to investigate the effect of music therapy on meth-addicted individuals (categorized by control and test groups) according to variables of sense of loneliness, life expectancy, agency thinking, and strategic thinking. According to Table 3, statistic $F$ (sense of loneliness) was 440.82 in posttest, and it was significant at $\mathrm{P}=0.001$ level, which indicated that there was a significant difference in sense of loneliness between the two groups. Effect size 0.94 showed that this difference in society was great and significant. The Fstatistic was also a pretest of loneliness (4.67), which was significant at the level of 0.05 . Accordingly, pretest had a significant effect on post-test scores, and the use of analysis of covariance was essential.

The results of covariance analysis showed that the corrected mean of the test group was 34.96 and the control group was 61.76 in sense of loneliness. Difference of mean in these two groups was -26.80 , which was significant at 0.001 . Therefore, it can be said that mean value of the test group that was sense of loneliness was significantly lower than the mean of the control group. With respect to these findings, the first hypothesis was confirmed, and it might be declared that music therapy might decrease the sense of loneliness in meth-addicted individuals.

After examining music therapy on the experimental and control groups in the post-test of total life expectancy in comparison to the pretest, it was observed that total life expectancy in the post-test (696.26) was significant at the level of 0.001 . This indicated a significant difference between the two groups. The effect size of 0.96 also showed that this difference was large and significant in society. Statistical $\mathrm{F}$ is also a predictor of total life expectancy (44.64), which is significant at the level of 0.001. Accordingly, pretest has a significant effect on post-test scores.

According to table three, $\mathrm{F}$ statistic for variables of agency thinking (201.23) and strategic thinking (165.82) is significant at 0.001. The findings indicate that there is a significant difference in these components between the control and test groups. The effect size for agency thinking (0.88) and strategic thinking (0.86) indicated that this difference was significant in society.

Generally, the mean and standard deviation of pretestposttest scores for life expectancy variable are presented in Table 4 for the two control and test groups. The difference in obtained mean between the control and test groups was 29.25, and standard deviation (0.79) was significant at 0.001. Therefore, total life expectancy in the test group was significantly higher than in the control group.

\section{Discussion}

The findings of this study indicate, for the first time, that music therapy can reinforce psychological constructs 


\begin{tabular}{|c|c|c|c|c|}
\hline Variables & Mean & Standard Deviation & K-SZ & P-Value \\
\hline \multicolumn{5}{|l|}{ Sense of loneliness } \\
\hline \multicolumn{5}{|l|}{ Pretest } \\
\hline Test & 64.47 & 5.29 & 0.76 & 0.59 \\
\hline Control & 62.27 & 4.92 & 0.68 & 0.73 \\
\hline \multicolumn{5}{|l|}{ Post test } \\
\hline Tests & 35.27 & 4.30 & 0.99 & 0.27 \\
\hline Control & 61.47 & 2.80 & 0.68 & 0.47 \\
\hline \multicolumn{5}{|l|}{ Agency thinking } \\
\hline \multicolumn{5}{|l|}{ Pretest } \\
\hline Test & 14.73 & 1.79 & 0.67 & 0.75 \\
\hline Control & 15.87 & 2.10 & 0.92 & 0.36 \\
\hline \multicolumn{5}{|l|}{ Post test } \\
\hline Tests & 24.67 & 1.49 & 0.79 & 0.55 \\
\hline Control & 15.27 & 1.94 & 0.95 & 0.32 \\
\hline \multicolumn{5}{|l|}{ Strategic thinking } \\
\hline \multicolumn{5}{|l|}{ Pretest } \\
\hline Test & 13.33 & 3.94 & 0.52 & 0.94 \\
\hline Control & 11.20 & 3.05 & 0.46 & 0.98 \\
\hline \multicolumn{5}{|l|}{ Post test } \\
\hline Tests & 25.60 & 2.5 & 1.27 & 0.08 \\
\hline Control & 13.14 & 2.78 & 0.55 & 0.91 \\
\hline \multicolumn{5}{|l|}{ Life expectancy } \\
\hline \multicolumn{5}{|l|}{ Pretest } \\
\hline Test & 27 & 3.74 & 0.67 & 0.75 \\
\hline Control & 27.93 & 5.23 & 0.64 & 0.79 \\
\hline \multicolumn{5}{|l|}{ Post test } \\
\hline Test & 50.07 & 2.73 & 0.70 & 0.71 \\
\hline Control & 29.53 & 4.08 & 0.71 & 0.68 \\
\hline
\end{tabular}

\begin{tabular}{|c|c|c|c|c|}
\hline Variable & Mean & F Statistic & P-Value & Effect Size \\
\hline \multicolumn{5}{|c|}{ Sense of loneliness } \\
\hline Pretest & 54.34 & 4.67 & 0.05 & 0.15 \\
\hline Posttest & 5131.84 & 440.82 & 0.001 & 0.94 \\
\hline \multicolumn{5}{|l|}{ Agency thinking } \\
\hline Post test & 24.89 & 201.23 & 0.001 & 0.88 \\
\hline \multicolumn{5}{|c|}{ Strategic thinking } \\
\hline Post test & 14.59 & 165.82 & 0.001 & 0.86 \\
\hline \multicolumn{5}{|l|}{ Life expectancy } \\
\hline Pretest & 211.03 & 44.64 & 0.001 & 0.62 \\
\hline Post test & 3300.82 & 698.26 & 0.001 & 0.96 \\
\hline
\end{tabular}

\begin{tabular}{l|c|c|c|c}
\hline \multicolumn{2}{l}{ Table 4. Final Estimated Mean of Total Life Expectancy in the Two Groups } \\
\hline Group & Mean & Mean Difference & Standard Error & Significance Level \\
\hline Test & 50.34 & 21.09 & 0.79 & 0.001 \\
\hline Control & 29.25 & & & \\
\hline
\end{tabular}


such as the sense of loneliness and life expectancy with respect to recovery of drug-addicted individuals. The results were consistent with the results of previous studies (5-7) regarding the effect of music therapy on the sense of loneliness and life expectancy. The findings indicate the positive effect of music therapy on the recovery of symptoms related to the sense of loneliness and life expectancy. The results indicating the positive effect of music therapy are consistent with the studies of Aletraris et al. (5) and Dingle et al. (20).

Sense of loneliness, seclusion, and lack of cohesive and stable interpersonal relationship are related to depression in terms of Semiology while listening to music leads to relaxation and reduce the depression $(20,21)$. Therefore, music therapy provides an opportunity to enhance group and interpersonal relationships for each participant so that they can share their thoughts, feelings, and emotions. When an individual with the sense of loneliness is involved in non-verbal relationship with music therapy, he can discover and identify certain aspects of himself and achieve responsibility for certain conditions in basic events of life by relying on identification of emotions in this process (21).

As it was mentioned earlier, achieving the sense of responsibility in the process of treatment, especially in the period of recovery and rehabilitation leads to effective efforts and positive prognosis in the treatment. Presence of an individual in music therapy sessions and knowing one's feelings help enhance the sense of control in life and improve mental and physiological conditions and reduce symptoms related to anxiety, stress, and sense of loneliness (7). To explain the finding that music therapy leads to improvement of life expectancy in drug-addicted individuals, it can be said that music, as a mediator of the relationship between therapist and client, increases the motivation by reducing negative behaviors, improves temper, and produces favorable events (10). An individual can review all ways to achieve certain goals by enhancing required motivation to move toward favorable goals by relying on personal responsibility (11).

On the other hand, music therapy triggers emotions and needs and hence provides the opportunity for increasing hope in the treatment process (19). In the present study, therefore, music therapy significantly provokes the emotions, feelings, and basically motivation to move toward certain goals, which are identified based on awareness about responsibility and internal capability of the patient. The results of the present study indicated music therapy can reduce the symptoms related to sense of loneliness and improve life expectancy in meth-addicted individuals. Since spiritual unconsciousness and its achievement by a patient are considered basic goals of music, music therapy can play a significant role as a facilitator for expressing fur- ther and deeper emotions and feelings in patients.

Individuals can understand the self again in a safe, cordial environment that is full of interpersonal trust and sympathy. Compared with the situation before research, the symptoms related to sense of loneliness were modified, and life expectance was improved significantly, which is the proof of efficiency of this treatment method. The present study indicates that music therapy, as a treatment method for drug-addicted individuals, can meet the needs of group and improve various psychological areas. Also, it is suggested that future research should investigate the effectiveness of group music therapy in improving other psychological constructs in addicted females and males who are attempting to quit.

\subsection{Limitations of the Research}

Limitations include lack of follow-ups due to problems of access to sample individuals and controlling the gender due to the limitation of access to female trials. Accordingly, it is suggested to evaluate treatment stability in future researches and perform the treatment method on both genders that are in the rehabilitation process after drug addiction.

\subsection{Suggestion}

It is suggested that the present study should be performed separately on both genders that are in the rehabilitation process after drug addiction. Moreover, the incorporated treatment method used in this study can be used in the treatment of other illnesses and healthcare areas.

\section{Acknowledgments}

The respected officials and deputy of research at University of Guilan are highly appreciated for their supports. This study is extracted from a Master's thesis by Mr. Reza Mohamadi Rad.

\section{Footnotes}

Authors' Contribution: All authors contributed equally to performing all stages of the paper.

Conflict of Interests: The authors declare no conflict of interest.

Ethical Approval: All the stages of the research are related to human participants based on ethical criteria of institutional/national research committee and according to the Declaration of Helsinki 1964 and its further amendments or ethical principles. Moreover, this study was approved and registered in the Ethics Committee of University of Guilan by code IR.GUMS.REC.1395.163. 
Funding/Support: This study was funded by Guilan University.

Informed Consent: Informed consent was obtained from all individual participants included in the study.

\section{References}

1. Galbraith N. The methamphetamine problem: Commentary on ... Psychiatric morbidity and socio-occupational dysfunction in residents of a drug rehabilitation centre. BJPsych Bull. 2015;39(5):218-20. doi: 10.1192/pb.bp.115.050930. [PubMed: 26755964]. [PubMed Central: PMC4706185].

2. Dehghani Z, Khodabakhshi-koolaee A. Effectiveness of group hope therapy on quality of life and resilience in addicted women. J Educ Community Health. 2017;4(1):28-34. doi: 10.21859/jech.4.1.28.

3. Khani Y, Barati H, Mollajan A, Mojtahedzadeh Faghihi M, Rimaz S. Investigating the trend and severity of withdrawal symptoms in methamphetamine users amongst homeless addicts. Int J High Risk Behav Addict. 2018;7(1). e66880. doi: 10.5812/ijhrba.66880.

4. Khodabakhshi-Koolaee A, Mosalanejad L, Gholami M, Massah O. Effectiveness of group hope therapy on the psychological indicators in women with addicted husbands. Iran Rehabil J. 2017;15(1):15-22. doi: 10.18869/nrip.irj.15.1.15.

5. Aletraris L, Paino M, Edmond MB, Roman PM, Bride BE. The use of art and music therapy in substance abuse treatment programs. $J$ Addict Nurs. 2014;25(4):190-6. doi: 10.1097/JAN.0000000000000048. [PubMed: 25514689]. [PubMed Central: PMC4268880].

6. Moasheri BN, Sharifzadeh G, Nahardan M, Soofi K. The effects of music therapy on depression among students. Mod Care J. 2016;13(1). e8846. doi: 10.17795/modernc.8846.

7. Nadimi M. Effectiveness of music therapy (active and passive) on quality of life and loneliness in old men. Biol Forum. 2015;7(2):22-7.

8. Castillo-Pérez S, Gómez-Pérez V, Velasco MC, Pérez-Campos E, Mayoral MA. Effects of music therapy on depression compared with psychotherapy. Arts Psychother. 2010;37(5):387-90. doi: 10.1016/j.aip.2010.07.001.

9. Gok Ugur H, Yaman Aktas Y, Orak OS, Saglambilen O, Aydin Avci I. The effect of music therapy on depression and physiological parameters in elderly people living in a Turkish nursing home: A randomized-controlled trial. Aging Ment Health. 2017;21(12):1280-6. doi: 10.1080/13607863.2016.1222348. [PubMed: 27592520].

10. Najafali S, Fakhri MK. The effect of music therapy on quality of life and Hope in elderly living in nursing homes. Indian Journal of Fundamental and Applied Life Sciences. 2014;5(S2):1909-13.

11. Soleimani E, Senobar L. The effectiveness of music therapy on anxietyaddiction traits in the rehabilitation phase non-pharmaceutical.J Addict Res. 2015;9(35):149-62.

12. Ingram I, Kelly PJ, Deane FP, Baker AL, Raftery DK. Loneliness amongst addictions populations: Validation of the social and emotional loneliness scale for adults - short version. Global Conference on Addiction Medicine and Behavioral Health. London, UK. 2019.

13. Erzen E, Cikrikci O. The effect of loneliness on depression: A meta-analysis. Int $J$ Soc Psychiatry. 2018;64(5):427-35. doi: 10.1177/0020764018776349. [PubMed: 29792097].

14. Hosseinbor M, Yassini Ardekani SM, Bakhshani S, Bakhshani S. Emotional and social loneliness in individuals with and without substance dependence disorder. Int J High Risk Behav Addict. 2014;3(3). e22688. doi: 10.5812/ijhrba.22688. [PubMed: 25632385]. [PubMed Central: PMC4295122].

15. Tam CH, Kwok SI, Lo TW, Lam SH, Lee GK. Hidden drug abuse in Hong Kong: From social acquaintance to social isolation. Front Psychiatry. 2018;9:457. doi: 10.3389/fpsyt.2018.00457. [PubMed: 30319464]. [PubMed Central: PMC6167475].

16. Mohammad-Najar N, Khoshnevis E, Banisi P. Effectiveness of positive thinking skills training on the hope and quality of life of drug-dependent people. Addict Health. 2017;9(3):120-8. [PubMed: 29657692]. [PubMed Central: PMC5894791].

17. Frankle VE. Man's search for meaning: An iutroduction to logotheraphy. New York, USA: Washington square press; 1963. p. 58-9.

18. Kermani Z, Khodapanahi M, Heidari M. [Psychometrics features of the Snyder Hope Scale]. J Appl Psychol. 2011;5(3 (19)):7-23. Persian.

19. Mezadehrabi Zadeh M, Salehi M, Kazemi N. Effectiveness of music, therapy, along with relaxation of blood pressure and pulse of the elderly with hypertension. Psychol Aging. 2017;2(4):293-303.

20. Dingle GA, Kelly PJ, Flynn LM, Baker FA. The influence of music on emotions and cravings in clients in addiction treatment: A study of two clinical samples. Arts Psychother. 2015;45:18-25. doi: 10.1016/j.aip.2015.05.005.

21. Argyris V, Karapetsa I, Rodopi ML. Coping with loneliness through music. ЕГКЕ $\Phi$ А $\triangle$ ¿. 2015;52:10-3. 